\title{
Preregistration house officers in the four Thames regions: I. Survey of education and workload
}

\author{
Thomas H S Dent, Jonathan H Gillard, Emma J Aarons, Helen L Crimlisk, \\ Penelope J Smyth-Pigott
}

\begin{abstract}
Objective-To assess the education and workload of preregistration house officers in the four Thames regions.

Design-Postal questionnaire.

Setting-Teaching and non-teaching hospitals in the four Thames regions.

Participants-1064 Preregistration house officers.

Results-Response rate was $70 \%$ (740 replies). Nine per cent of house officers $(66 / 729)$ worked a rota of one in two. The average house officer had 20.4 inpatients under his or her care and admitted 23.2 patients per week. Sixty two per cent of house officers $(459 / 740)$ felt that they spent an excessive amount of time on non-medical tasks of no educational merit; $75 \%(546 / 725)$ had never received adequate guidance on breaking bad news and $64 \%$ (467/ 729) had never received adequate guidance on pain control; 34\% (249/731) did not feel confident that they could perform cardiopulmonary resuscitation unsupervised. House officers would tend to recommend their post to a friend.

Conclusions-There are deficiencies in preregistration training in the four Thames regions. The General Medical Council's requirements are not being heeded.
\end{abstract}

\section{Introduction}

To follow a career in medicine a doctor must become fully registered with the General Medical Council (GMC), usually by satisfactory completion of a year in accredited house officer posts. These posts are therefore intended by the GMC to be training posts, providing basic clinical experience.' The need to provide service to the hospital may, however, mean that the educational value of the post is compromised. ${ }^{2}$

A questionnaire survey was carried out to obtain data about the workload and education of preregistration house officers in the four Thames regions. The effect of service commitments on formal education and the extent of compliance with the GMC's recommendations were assessed.

\section{Method}

The survey was conducted by postal questionnaire, each respondent being assured of confidentiality. After a pilot study the full survey was conducted in December 1988 and January 1989. A questionnaire was sent to all 1064 of the preregistration house officers

TABLE I - Percentage (number) of house officers who thought that they had received adequate guidance in important areas of practice

\begin{tabular}{lccc}
\hline & $\begin{array}{c}\text { Adequate } \\
\text { guidance }\end{array}$ & $\begin{array}{c}\text { Inadequate } \\
\text { guidance }\end{array}$ & Total \\
\hline Cardiopulmonary resuscitation & $82(603)$ & $18(131)$ & 734 \\
Death certification & $53(388)$ & $47(341)$ & 729 \\
Pain control & $36(262)$ & $64(467)$ & 729 \\
Breaking bad news & $25(179)$ & $75(546)$ & 725 \\
Major accident plan & $12(88)$ & $88(634)$ & 722 \\
\hline
\end{tabular}

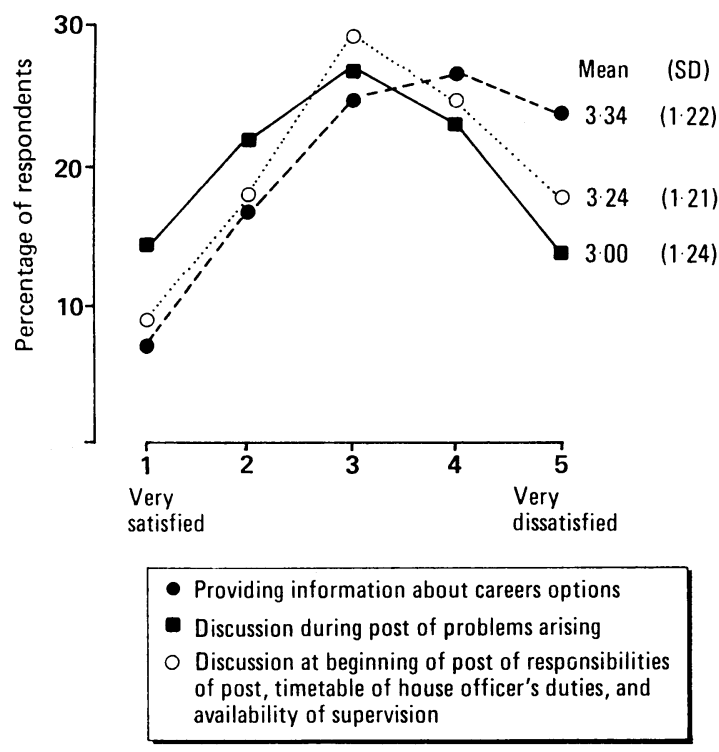

Degree of house officers' satisfaction with specified functions of consultants

working in the four Thames regions. Non-responders were followed up by sending a second questionnaire and covering letter. The questionnaire requested information on the respondent and the post, the content of any induction courses, the provision of educational supervision, the workload, the acquisition of clinical experience, confidence in performing practical procedures, provision of and attendance at formal educational meetings, and the extent to which the respondent would recommend the post to a friend. Space was provided in each section for comments.

\section{Results}

A total of 740 questionnaires were returned, giving a response rate of $70 \%$. Of the respondents, $417(56 \%)$ were male; 357 (48\%) were house physicians, and 383 $(52 \%)$ were house surgeons. Overall, 691 (93\%) had received their clinical training in a London teaching hospital. Not all respondents answered every question.

In all, 414 house officers $(56 \%)$ had attended at least one induction course. House officers were asked whether they had at any time received guidance in a number of important areas including cardiopulmonary resuscitation, breaking bad news, and pain control; table I shows their responses.

The figure shows the degree of house officers' satisfaction with their educational supervision. House officers were asked whether they were satisfied that their consultant or any other consultant had provided career guidance; discussed any problems encountered during the post; and discussed, at the beginning of the post, the responsibilities, timetable of duties, and availability of supervision. These activities have been defined by the GMC as the responsibility of a house officer's educational supervisor, who in most cases is the consultant

The most common on call rota (not including
Dr J H Gillard, Renal Unit, Leicester LE5 4PW. 
TABLE II - Rotas worked by house officers

\begin{tabular}{lc}
\hline On call rota & $\begin{array}{c}\%(\mathrm{No}) \text { of } \\
\text { respondents } \\
(\mathbf{n}=729)\end{array}$ \\
\hline One in two & $9(66)$ \\
One in three & $67(188)$ \\
One in four & $23(171)$ \\
One in five or more & $1(4)$ \\
\hline
\end{tabular}

TABLE III - House officers' perception of amount of time spent on administrative work

\begin{tabular}{lc}
\hline & $\begin{array}{c}\%(\mathrm{No}) \text { of } \\
\text { respondents } \\
(\mathrm{n}=740)\end{array}$ \\
\hline 1 Reasonable & $5(36)$ \\
2 [Acceptable] & $12(87)$ \\
3 [Moderate] & $21(158)$ \\
4 [Excessive] & $41(301)$ \\
5 Grossly excessive & $21(158)$ \\
\hline Mean $(\mathrm{SD})^{\star}$ & $3.63(1 \cdot 08)$ \\
\hline
\end{tabular}

« Subjective scale.

internal cover) was one night in three. Of the 729 respondents to this question, $66(9 \%)$ were still working a one in two rota and $240(33 \%)$ worked a one in two for some weeks of the post; 379 house officers (52\%) had internal cover. Only $175(24 \%)$ worked a one in four rota or better (table II).

The average time at which house officers began work each morning was 0822 (SD $28 \mathrm{~min})$. The average time they finished was 1802 (52 $\mathrm{min})$.

At any one time a house officer was caring for an average of $20 \cdot 4$ inpatients $(9 \cdot 13)$. Seventy seven $(11 \%)$ had more than 30 patients, and 96 (13\%) had 10 patients or fewer. During a typical week house officers clerked an average of $10 \cdot 0$ emergency cases $(5 \cdot 69), 8 \cdot 35$ routine cases $(6 \cdot 43)$ and $4 \cdot 83$ day cases $(3 \cdot 93)$.

A proportion of house officers' time is taken up by administrative work such as organising admissions, discharges, and investigations and chasing up results (table III). Only 33 house officers (5\%) thought that they spent a reasonable amount of time on this, and 459 $(62 \%)$ thought that it was excessive or grossly excessive.

Of the 406 (55\%) house officers who were expected to provide care for private patients, only $38(9 \%)$ had received payment for this.

One hundred and seven house officers (14\%) thought that they were seeing too few patients to gain sufficient clinical experience, $517(70 \%)$ that they were gaining about the right amount of clinical experience, and $116(16 \%)$ that they were seeing so many patients that they did not have enough time to learn from their post. Table IV shows the confidence with which house officers approached various clinical procedures.

Of the 725 house officers answering this question, only $389(53 \%)$ considered that there was a sufficient number of meetings at their hospital. Moreover,

TABLE IV-Confidence with which house officers approach various clinical procedures

\begin{tabular}{|c|c|c|c|c|c|}
\hline & \multicolumn{4}{|c|}{$\%(\mathrm{No})$ of respondents } & \multirow[b]{2}{*}{ Total } \\
\hline & $\begin{array}{l}\text { Confident in } \\
\text { performing } \\
\text { unsupervised }\end{array}$ & $\begin{array}{c}\text { Would } \\
\text { "have a go" } \\
\text { unsupervised }\end{array}$ & $\begin{array}{l}\text { Would not } \\
\text { perform unless } \\
\text { adequately } \\
\text { supervised }\end{array}$ & $\begin{array}{l}\text { Would refuse } \\
\text { to perform } \\
\text { even if } \\
\text { supervised }\end{array}$ & \\
\hline Inserting a Venfon catheter & $100(736)$ & & & & 736 \\
\hline Urinary catheterisation of male patient & $99(728)$ & $1(7)$ & $<1(1)$ & & 736 \\
\hline \multicolumn{6}{|l|}{ Using ECG machine to produce a 12 lead } \\
\hline ECG & $96(707)$ & $3(22)$ & $1(7)$ & & 736 \\
\hline Arterial blood gas sampling & $94(690)$ & $6(41)$ & $1(5)$ & & 736 \\
\hline Urinary catheterisation of female patient & $81(594)$ & $15(112)$ & $2(12)$ & $2(12)$ & 730 \\
\hline Simple suturing & $79(577)$ & $18(132)$ & $3(21)$ & $<1(2)$ & 732 \\
\hline Basic cardiopulmonary resuscitation & $66(482)$ & $31(226)$ & $3(23)$ & & 731 \\
\hline Inserting nasogastric tube & $52(421)$ & $35(260)$ & $7(52)$ & $<1(1)$ & 734 \\
\hline Ear syringing & $45(329)$ & $32(230)$ & $21(156)$ & $2(12)$ & 727 \\
\hline Pleural fluid aspiration & $40(296)$ & $29(209)$ & $30(222)$ & $1(6)$ & 733 \\
\hline Excision of sebaceous cyst & $40(291)$ & $25(181)$ & $33(241)$ & $3(19)$ & 732 \\
\hline Paracentesis & $31(228)$ & $27(194)$ & $37(267)$ & $5(39)$ & 728 \\
\hline Lumbar puncture & $21(154)$ & $26(191)$ & $51(375)$ & $2(16)$ & 736 \\
\hline Joint aspiration & $15(113)$ & $31(230)$ & $51(372)$ & $2(17)$ & 732 \\
\hline Suprapubic aspiration of urine & $14(101)$ & $29(211)$ & $54(398)$ & $3(25)$ & 735 \\
\hline Endotracheal intubation & $12(87)$ & $48(353)$ & $38(277)$ & $2(14)$ & 731 \\
\hline Inserting chest drain & $10(75)$ & $25(185)$ & $63(460)$ & $2(14)$ & 734 \\
\hline Reduction of dislocated shoulder & $5(33)$ & $21(150)$ & $66(481)$ & $9(62)$ & 726 \\
\hline Inserting central venous pressure line & $5(35)$ & $16(119)$ & $73(535)$ & $6(43)$ & 732 \\
\hline Bone marrow aspiration & 2(14) & $8(56)$ & $79(578)$ & $11(83)$ & 731 \\
\hline Appendicectomy & $2(18)$ & $7(51)$ & $78(564)$ & $13(94)$ & 727 \\
\hline Inserting pacing wire & $1(7)$ & $4(27)$ & $73(536)$ & $22(163)$ & 733 \\
\hline
\end{tabular}

TABLE v-Extent to which house officers would encourage or discourage friends to apply for their posts

\begin{tabular}{lc}
\hline & $\begin{array}{c}\%(\mathrm{No}) \text { of } \\
\text { respondents } \\
(\mathrm{n}=726)\end{array}$ \\
\hline 1 Strongly encourage & $29(210)$ \\
2 Encourage & $41(298)$ \\
3 Neutral & $20(145)$ \\
4 Discourage & $6(45)$ \\
5 Strongly discourage & $4(28)$ \\
\hline Mean (SD) & $2 \cdot 15(1 \cdot 03)$ \\
\hline «Subjective scale. &
\end{tabular}

$151(20 \%)$ reported that they were almost invariably prevented from attending meetings by clinical commitments, and only $44(6 \%)$ responded that clinical commitments never prevented them from attending educational sessions

The final question asked house officers how much they would encourage or discourage a friend who was considering applying for their post. Table V shows the response to this question.

\section{Discussion}

The GMC places great importance on the preregistration year, yet there have been several studies from single medical schools reporting poor educational provision, excessive workload, and widespread discontent among house officers. ${ }^{23}$ There has, however, been no attempt to assess how widespread the problems are, and the GMC's latest recommendations' have been issued without any published assessment of whether the council's previous guidance has been heeded. Our survey was undertaken partly to provide a point of reference from which the effect of the latest recommendations, and new endeavours on the issue of hours of work can be measured.

Our response rate of $70 \%$ is high for a postal questionnaire, and the response rates of house physicians and house surgeons did not differ significantly. Some of the respondents expressed great disappointment with their posts in the comments sections of the questionnaire, and those with the strongest opinions may have been the most motivated to reply.

\section{PREVIOUS EDUCATION AND INDUCTION COURSES}

The transition from medical student to house officer is a major and abrupt one. An induction course should facilitate this transition by providing revision of basic skills, such as cardiopulmonary resuscitation, and information about administrative arrangements and local practice. Such introductory guidance is recommended by the GMC. Unfortunately, 265 house officers $(36 \%)$ were not able to attend such a course. One house officer attended the beginning of his course but said "my bleep was going off so often that I missed most of it." Of the 474 who answered the question on satisfaction with their induction courses, $199(42 \%)$ thought that the quality of the courses was unsatisfactory.

Reviewing all their undergraduate training, any induction course, and experience of five months or more as a house officer, 131 respondents (18\%) said that adequate guidance on cardiopulmonary resuscitation had never been given to them, an issue that is discussed further below. It has been shown that $72 \%$ of consultants and general practitioners think that there is "insufficient training in the skills of doctor-patient communication,"4 something that patients would doubtless endorse. Despite this, almost three quarters of house officers had never been adequately taught how to break bad news, a task that is often delegated to the most junior member of the team.' Almost two thirds had never been adequately taught how to treat pain. These findings are surprising in view of the GMC's specific guidance that training in communication and in care for dying patients is to be part of the preregistration year. Furthermore, the Wilkes report recommended in 1980 that the teaching of these skills should begin at undergraduate level, ${ }^{6}$ and these results therefore reflect poorly on the performance of London medical schools.

\section{EDUCATIONAL SUPERVISION}

Generally, house officers were not satisfied with their consultants' discussions at the beginning of the post or with help with problems as they arose. Moreover, more than half of house officers did not get satisfactory career guidance from their consultants (figure), a particular cause for concern in view of the greater importance of early career decisions that will result from the implementation of recommendations in Achieving a Balance.

\section{WORKLOAD}

The elimination of rotas more onerous than one in three has been the policy of the Department of Health since 1982. Nevertheless, about one in 11 of our respondents were still working one night in two, which produced feelings of despair in some house officers. One who was working a one in two rota wrote, "The 
on-call requirement is unacceptable from any point of view. In any other situation this type of sleep deprivation would invite the attention of Amnesty International." One third of house officers worked a one in two for some weeks of the post (their rota was a one in three with internal cover). Only one quarter of house officers worked a one in four rota or better.

The GMC recommends that the number of patients that each house officer is asked to care for should not normally be greater than $30 .^{1}$ This seemed to be adhered to, with just over one in ten house officers exceeding this at the time of reply. On the other hand, more than one in eight had 10 patients or fewer, which may be too few to provide sufficient experience. The number of patients admitted per week in each category (emergency, elective, and day case) seemed appropriate.

Much time was consumed on tasks devoid of educational value, such as organising admissions and investigations or chasing results. For many, this was the most frustrating part of their job. One house officer wrote, "They have sacked the phlebotomists and replaced them with housemen. I spend three hours a day doing bloods and taking them to the labs" and another commented, "Most of the time, it is all I seem to do." A third was surprised that we asked about this area: "These jobs are the house job."

It is surprising that over half of the house officers were expected to care for their consultants' private patients. This task is not part of their job description and is often a distraction from their NHS work, which is their only legitimate activity in working hours. One house physician wrote, "I spend nearly one third of my time looking after private leukaemic patients." It is perhaps not so surprising that fewer than one in ten of these house officers were paid for this work.

\section{ACQUIRING CLINICAL EXPERIENCE}

Three in ten house officers thought that they were seeing an inappropriate number of patients. This figure is unacceptably high; furthermore, it conceals the effect of highly specialised case mixes on clinical experience. One house surgeon in a teaching hospital had spent three months in reconstructive urology followed by three months in a surgical firm with a vascular interest; as a result, he had seen only one cholecystectomy and one colonic resection, which plainly falls far short of what the GMC expects. He commented, "I would feel unable, as a GP, to give detailed information to patients needing these operations."

\section{PRACTICAL PROCEDURES}

The most alarming finding in this section of the questionnaire was the lack of confidence with which house officers approached basic cardiopulmonary resuscitation. Less than two thirds felt confident in performing it unsupervised, as they would have to do if they were the first doctor to arrive at a cardiac arrest, whether in hospital or outside. This response was elicited after house officers had had five years of undergraduate medical education and at least five months in house officer posts. The house officers have either attended too few cardiac arrests in this period or are not learning from their attendance about what they should do. Alarm should be all the greater because of the many studies showing that even doctors who believe themselves to be competent at cardiopulmonary resuscitation consistently fail to show their competence when formally tested ${ }^{10}$ : many of those in our survey who believed that they could maintain cerebral oxygenation would not be doing so. It is distressing that hospitals are failing to train house officers to act correctly when faced with a cardiac arrest. Because resuscitation skills are lost rapidly" previous authors have called for compulsory testing and retesting of these skills to be a condition of employment in junior general medical posts. This deficiency of training should be corrected urgently.

\section{FORMAL EDUCATIONAL MEETINGS}

There is clear evidence that house officers were not being provided with the education that the GMC requires: "Trainees should also be encouraged to reinforce their clinical experience by attending any appropriate lectures or courses organised by Clinical Tutors, pathology demonstrations and multi-disciplinary meetings concerning topics of general interest, such as alcohol and drug-related problems, and by involvement in case conferences and post mortems, especially where these concern the trainee's own patients."

Almost half the house officers thought that there were not enough educational meetings at their hospitals, though they were generally satisfied with their quality. Nearly half reported that they were frequently prevented by clinical commitments from attending what meetings there were. In busy hospitals some way must be found to protect from interruption the few opportunities for formal education that house officers have-one arrangement that was mentioned was all bleeps being left with the postgraduate centre administrator during meetings, with messages being taken and the meeting disturbed only in an emergency. The practice of formal educational sessions finishing a poor second to service commitments must cease, especially in the light of our evidence that so much of what house officers are asked to do is devoid of any educational value.

\section{RECOMMENDATION OF POST}

Despite the weary and unhappy tone of so many of their responses to our questionnaire, house officers would still tend to recommend their post to a friend. This seems to indicate a general sense of enjoyment in the face of adversity, but it may equally stem from a feeling that their post, though unsatisfactory, is better than most. We suspect that most house officers are expecting the worst from their preregistration year, are not surprised by what they experience, and would therefore not deter an equally realistic friend from applying.

We are aware of increasing evidence of professional disenchantment and psychiatric morbidity among preregistration house officers. ${ }^{12}{ }^{13}$ In their comments the house officers who replied to our questionnaire provided ample confirmation that these concerns are well founded. One wrote, "If I were 18 again I wouldn't do medicine-I would work in a bank for decent pay and hours and conditions." Another commented, "We feel abandoned and unthanked."

The problems that our study has identified are important and urgent, and we endorse the efforts of all those who are seeking to solve them.

1 General Medical Council. Recommendations on general clinical training. London: GMC, 1987.

2 McManus IC, Lockwood DNJ, Cruickshank JK. The pre-registration year: chaos by consensus. Lancet 1977;i:413-6.

3 Christie RAS. The pre-registration house appointment: a survey in Manchester. Med Educ 1980;14:210-3.

+ Wakeford RE, Allery L. Doctors' attitudes, medical philosophy and political views. Br Med F 1986;292:1025-7.

5 Jolly BC, Macdonald MM. Education for practice: the role of practical experience in undergraduate and general clinical training. Med Educ 1989;23:189-95.

6 Standing Medical Advisory Committee. Report of a working group on terminal care. London: Department of Health and Social Security, 1980. (Wilkes
report.)

7 United Kingdom Health Departments, Joint Consultants Committee, Chairmen of Regional Health Authorities. Hospital medical staffing: achieving a balance: plan for action. London: Department of Health and Social Security, 1987.

8 Department of Health and Social Security. Circular $E L(88)(P) 82$. London: DHSS, 1982. 
9 Lowenstein SR, Libby LS, Mountain RD, et al. Cardiopulmonary resuscitation by medical and surgical house officers. Lancet 1981;ii:679-8

10 Skinner DV, Camm AJ, Miles S. Cardiopulmonary resuscitation skills of preregistration house officers. Br Med $\mathcal{F}$ 1985;290:1549-50.

11 Mancini ME, Kaye $W$. The effect of time since training on house officers retention of cardiopulmonary resuscitation skills. Am $\mathcal{f}$ Emerg Med 1985;1:31-2
12 Firth-Cozens J. Emotional distress in junior house officers. Br Med $\mathcal{f}$ $1987 ; 295: 533-6$

13 King RC. A logbook for pre-registration house officers. $\operatorname{Br} \mathcal{F}$ Hosp Med 1989;41:111

\section{Comparison of education and workload in teaching and non-teaching hospitals}

\begin{abstract}
Objective-To detect differences in the education and workload of preregistration house officers working in teaching and non-teaching hospitals.

Design-A postal questionnaire.

Setting-Teaching and non-teaching hospitals in the four Thames regions.

Participants - 1064 Preregistration house officers.

Results-Response rate was $61 \%$ for teaching hospitals and $73 \%$ for non-teaching hospitals. House officers in teaching hospitals had significantly fewer inpatients under their care (house physicians $16.9 v 22.9$, house surgeons $17.9 \vee 20.3$ ) and admitted fewer emergency patients per week (house physicians $7.7 v 12.7$, house surgeons $6.5 v 9.8$ ). More house officers in teaching hospitals reported that they had too few patients to provide adequate clinical experience. More of their time was consumed by administrative activities devoid of educational value.

Conclusion-Preregistration house officer posts at teaching hospitals provide less clinical activity and are perceived as less educationally satisfactory by their holders than those elsewhere.
\end{abstract}

\section{Introduction}

There is widespread concern that preregistration house officer posts in teaching hospitals may offer a less satisfactory training than those elsewhere. The provision of regional and supraregional services means that some house officers may undertake a relatively greater volume of highly specialised work. There are also frequent shortages of beds for emergency and elective admissions at teaching hospitals. Commitments of consultants at other hospitals may reduce their ability to teach and support. Ironically, these posts, which may yield an inadequate clinical education, are more keenly sought after by graduating medical students, who believe that the posts confer an advantage when applying for senior house officer posts.

A questionnaire survey was carried out to test the hypotheses that preregistration house officer posts at

TABLE I-Induction courses and guidance of house physicians in teaching and non-teaching hospitals in Thames regions

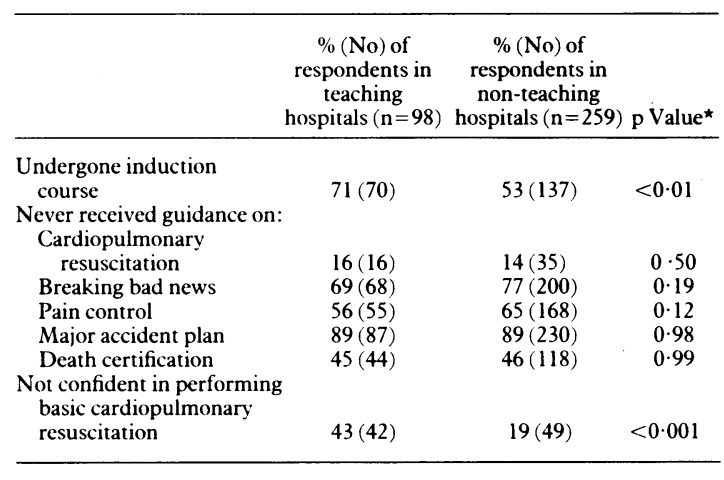

^Mann-Whitney U test. teaching hospitals offer a poorer education and less job satisfaction.

\section{Method}

The survey was conducted by postal questionnaire to all 1064 preregistration house officers in the four Thames regions. The method is described in the previous paper.' The following hospitals were regarded as "teaching": Charing Cross, Guy's, King's, The London, Middlesex, Royal Free, St Bartholomew's, St George's, St Mary's, St Thomas's, University College, and Westminster.

Data were analysed with the Mann-Whitney U and Wilcoxon rank sum $W$ tests, using the SPSS $X$ programmes at the University of London computer centre.

\section{Results}

MEDICINE

The proportions of male and female house physicians in teaching and non-teaching hospitals were identical: 54\% men (53 of 98 respondents from teaching hospitals and 140 of 259 from non-teaching hospitals). This is contrary to the prevailing idea that women have more success in obtaining these generally more sought after posts.

House physicians in teaching hospitals were significantly more likely to have attended an induction course than those at non-teaching hospitals $(71 \% v 53 \%)$; $\mathrm{p}<0.01$ ) (table I). They were no more likely, however, either as medical students or since, to have received adequate guidance on breaking bad news $(69 \%$ v $77 \%$; $\mathrm{p}=0 \cdot 19)$, pain control $(56 \% v 65 \% ; \mathrm{p}=0 \cdot 12)$, or cardiopulmonary resuscitation $(16 \% v 14 \% ; \mathrm{p}=0 \cdot 50)$. As cardiopulmonary resuscitation should form part of most hospitals' induction courses adequate guidance might be expected to be more common at teaching hospitals. The proportion of respondents who lacked confidence performing basic cardiopulmonary resuscitation without supervision was significantly higher at teaching hospitals ( $43 \% v 19 \% ; \mathrm{p}<0.001)$, which indicates that inadequate guidance was not the reason for most house physicians' lack of confidence in this technique. The problem must therefore have been lack of opportunity to practise.

Not surprisingly, significantly more house physicians at teaching hospitals worked in subspecialties $(85 \% v 60 \% ; \mathrm{p}<0.001$ ). (table II), and from their comments it was clear that some of these specialties were esoteric and perhaps unsuitable to such an early stage of training. The effect that the house physicians thought that this had on their education was not measured directly but was reflected in answers later in the questionnaire.

There was no difference in the on call rotas according to contract, but significantly more house physicians in teaching hospitals were involved in internal cover $(62 \% v 45 \% ; \mathrm{p}<0.01)$. In many cases this meant a one in two rota for some weeks of the post. They were more 